\title{
Lip print pattern identification of Deutromalayan subrace using a modification of lip print formulation technique as forensic odontology application
}

\author{
Evirilia*, Belly Sam*, Fahmi Oscandar* \\ *Department of Dentomaxillofacial Radiology Faculty of Dentistry, Universitas \\ Padjadjaran, Indonesia
}

\begin{abstract}
Introduction: Every individual has a different lip print pattern that facilitates personal identification. Every individual has the physical characteristics that are different from other individuals. The physical characteristics can be an identity for the individual. The purpose of this research was to investigate the lip print pattern among Deutromalayan subrace with a modification of lip print formulation technique. Methods: A descriptive research was conducted among 82 male and female students of 2008 batch students of Faculty of Dentistry Universitas Padjadjaran. The research was an observation of lip print from each subject in the digital view from the scanning of a lip seal. The observation was carried out on all parts of the fissure in the subject's lip print. The data was then analysed to a lip print pattern formulation based on fingerprint formulation. Results: Lip print pattern of Deutromalayan subrace was different among each other and clarified in a formulation consisted of elements from the central fissure type, amount of median fissure, fissure tracing and all lip print type. Conclusion: Lip print pattern among Deutromalayan subrace was identified by modification of lip print formulation technique that was clarified on the formulation.
\end{abstract}

Keywords: Lip print pattern, lip print formulation, Deutromalayan subrace.

\section{INTRODUCTION}

Lately mortality resulting from criminal acts or accidents have been rising sharply. The victims can't be easily identified due to several factors such as the physical condition of the victims who have suffered severe damage or lack of identity around the scene. This requires the medical team to work better in identifying the victims.

Along with the advancement of science and technology, forensic science has evolved into the science of forensic medicine and forensic science of dentistry (forensicodontology). Forensic dentistry is the branch of dentistry that relating to the handling, examination and evaluation and presentation of evidence objects with appropriate gear for the sake of justice. ${ }^{1}$

Every individual has the physical characteristics that are different from other individuals. The physical characteristics can be an identity for the individual. One of the physical characteristics that can be identified in individuals in forensic dentistry is lip prints. Own lip prints as well as fingerprints are the expression of different 
genes in each individual. ${ }^{2}$ According Tsuchihashi lip prints are handed down from parents, but there are similarities in print everyone's lips. According to Mc Donell two identical twins who are indistinguishable physically have different lip prints. ${ }^{3}$ In Indonesia, public awareness for oral and dental care is still quite low, so that the level of public visits to the dentist are low.

This resulted in data regarding dental care and mouth at the dentist or other health care facilities it is still quite lacking. Meanwhile in forensic dentistry, lip prints can be an alternative to supporting data when the data regarding dental identification is not available.Lip has a pattern that can be classified into several types can be used in the identification process. ${ }^{2}$

Data supporting identification in some cases can be derived not only from the hard tissue but also soft tissue. The actors in a criminal act can leave fingerprints lips to cutlery he used, the victim's body or other objects that come into contact with actors lip. Lip prints left behind can be used in identifying the perpetrators or the victims unidentified.

The use of lip prints in the forensic dentistry to identify someone in criminal cases and accidents, such as theft or accidents with soft tissue conditions contained in the face of victims and perpetrators is efficient, but due to limited data and knowledge about this lip print identification, it is still rarely performed. Lip print identification is used for this most still use quadrant division method, with this method the accuracy of the appearance of lip prints with the same pattern in a larger population will increase.

The identification using fingerprints quite successful in the process of personal identifier. The method of personal identification through fingerprints has a high level of specificity to their formula of fingerprint that can distinguish an individual with other individuals. Formulation fingerprints based on the shape of goods as well as details of the lines of a set of fingerprints. ${ }^{4}$ Each section fingerprints taken as part of the fingerprint formula is different for every individual.

Fingerprints used as one means of identification because it has unique properties (different foreach individual), will notchangeunless it gets a serious accident(immutability)and clinging for life on each individual(perennialnature),even still after the individual dies world for his body has not decomposed. ${ }^{5}$ In addition, the fingerprint can be formulated and classified mathematically. 6 As with fingerprints, lip prints on a person is a physical characteristic that is unique. Several studies have reported that lip prints individualized, permanent and unchanging from birth to death. ${ }^{7}$ When compared with fingerprints, lip prints have the same properties as the fingerprint, which can be used in identification.

Associated with this, the authors were interested to determine the formula for lip prints based on the formulation of a fingerprint. The formula will then be applied to each subjects that and different pattern of lip print will be compared. The purpose of this research is to find out the lip print pattern among Deutromalayan subrace spesification modification of lip print using formulation technique.

\section{METHODS}

The type of research method used in this research is descriptive. The study population is students Subrace Deutromelayu Dentistry Unpad batch 2008. Research will be conducted on students Subrace Deutromelayu Dentistry - Unapd batch 2008 . Sampling was done by using purposive sampling. The number of samples obtained by using the formula Slovin. ${ }^{8}$ Samples are taken from 82 students out of 103 students.

Criteria for inclusion in this study were students of Faculty of Dentistry, University of Padjadjaran class of 2008, including in Subras Deutromelayu without abnormalities such as swelling of the lips, cleft lip, dry mouth, infections and neoplasms, as well as willing to be the subject of study by completing the informed consent. The steps in the research process is the preparation of studies, taking fingerprints and lip prints observation lips and lip prints formula determination.

\section{RESULTS}

\section{Determining fingerprint patterns lips on each quadrant}

Observation of the lip print pattern on a subject that has been divided into six quadrants. 


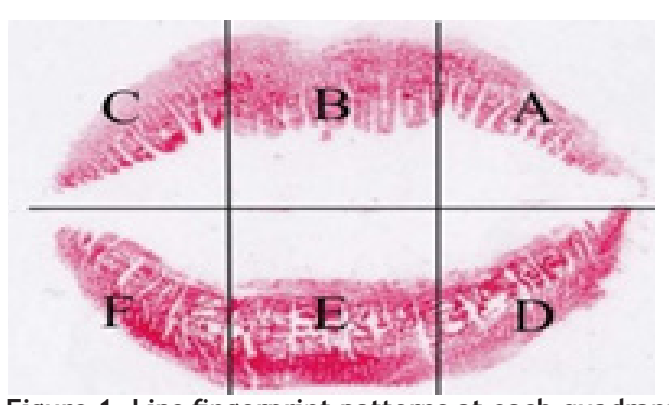

Figure 1. Lips fingerprint patterns at each quadrant

\section{Determining the central flow lip print formula}

Central grooves of the upper lip is located below the deepest basin Cupid's bow and the lower lip is located below the deepest hollows of the line where the upper lip and lower lip. These grooves are given the symbol "S".

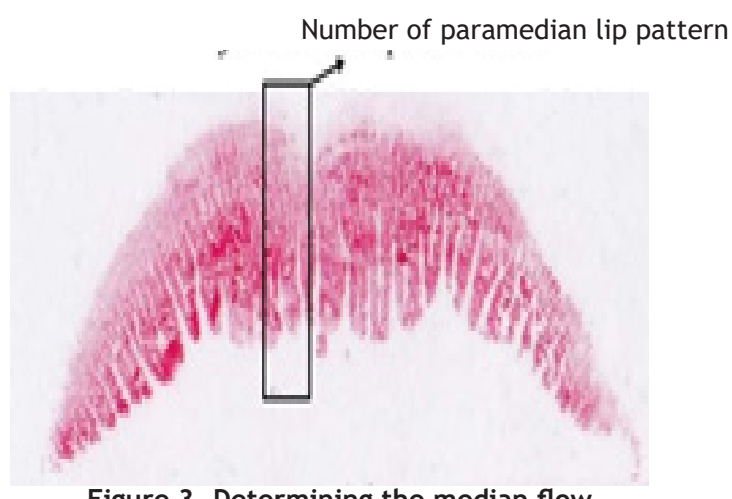

Figure 3. Determining the median flow

\section{Tracing fissure}

Fissure tracing performed by tracing the flow of the line following the course right beside the central grooves ranging from boundary to boundary meeting vermillion upper lip and lower lip. Grain direction in-tracing should be the same as the direction of flow of the median pre-determined. These grooves are given the symbol " $\mathrm{F}$ "

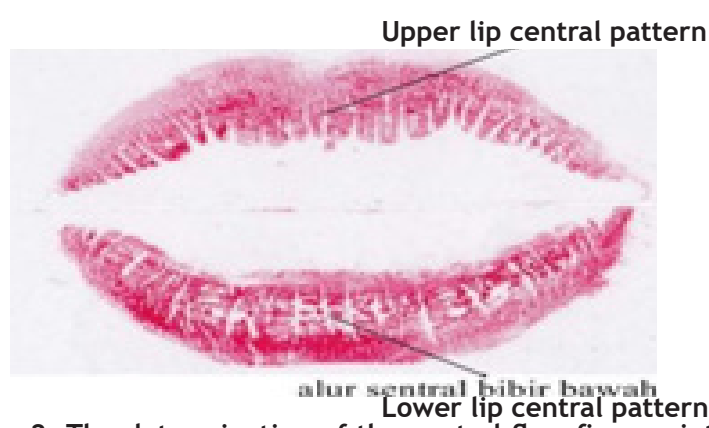

Figure 2. The determination of the central flow fingerprin lips

\section{The median groove}

Median groove is determined by counting the number of grooves located between the central groove and the next groove that have different types with a central groove. Directions grooves taken from the right by the symbol "Pm a" and grooves taken from the left by the symbol "Pm b".

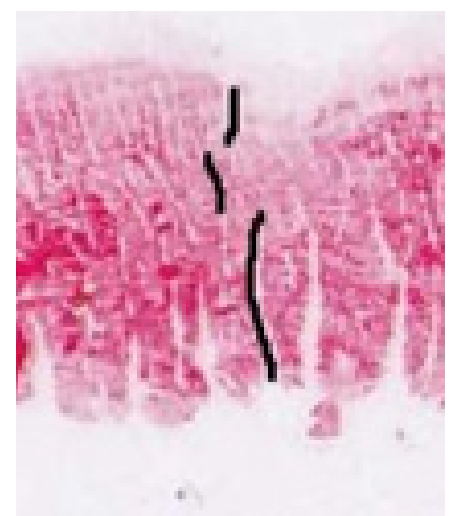

Figure 4. Fissure tracing

\section{Combination overall lip print type}

Lip print mode overallspecified from left to right on each of the upper lip and lower lip. All types of lip prints on each of the upper and lower lips are grouped differently.

Table 1. Observations of the lip prints on each quadrant

\begin{tabular}{|c|c|c|c|c|c|c|c|c|c|c|c|c|c|c|}
\hline \multirow{4}{*}{$\begin{array}{c}\text { No } \\
\\
1\end{array}$} & \multirow{4}{*}{$\begin{array}{l}\text { Type } \\
\text { Lip } \\
\text { print }\end{array}$} & \multicolumn{13}{|c|}{ Quadrants } \\
\hline & & \multirow{2}{*}{\multicolumn{3}{|c|}{$\begin{array}{l}1 \\
\%\end{array}$}} & \multirow{2}{*}{\multicolumn{2}{|c|}{$\begin{array}{l}2 \\
\%\end{array}$}} & \multirow{2}{*}{\multicolumn{2}{|c|}{$\begin{array}{l}3 \\
\%\end{array}$}} & \multirow{2}{*}{\multicolumn{2}{|c|}{$\%$}} & \multirow{2}{*}{\multicolumn{2}{|c|}{$\begin{array}{l}5 \\
\%\end{array}$}} & \multirow{2}{*}{\multicolumn{2}{|c|}{6}} \\
\hline & & & & & & & & & & & & & & \\
\hline & & 6 & 7.31 & 13 & 15.85 & 7 & 8.54 & 12 & 14.63 & 37 & 45.12 & 18 & 21.95 & 18.91 \\
\hline 2 & & 27 & 32.93 & 23 & 28.05 & 31 & 37.80 & 13 & 15.86 & 23 & 28.05 & 13 & 15.85 & 26.43 \\
\hline 3 & & 42 & 51.21 & 18 & 21.95 & 40 & 48.78 & 57 & 69.51 & 17 & 20.73 & 50 & 60.98 & 45.54 \\
\hline 4 & & 5 & 6.10 & 4 & 4.88 & 3 & 3.66 & - & - & - & - & - & - & 2.44 \\
\hline 5 & & - & - & 9 & 10.97 & - & - & - & - & - & - & - & - & 1.83 \\
\hline 6 & & 2 & 2.24 & 15 & 18.3 & 1 & 1.22 & - & - & 5 & 6.10 & 1 & 1.22 & 4.85 \\
\hline
\end{tabular}


Table 1 shows the lip pattern appears most is type II with lip prints emergence average of 45.54\%. Lip pattern appears least on most quadrant is a lip print type IV with an average appearance of lip prints by $1.83 \%$. Quadrant lips that most shows variation lip prints are quadrant 2 , where 6 patterns of lips can be seen in the quadrant.

Figure 2. The determination of the central flow lip print

\begin{tabular}{cccccc}
\hline \multirow{2}{*}{ No. } & Type & & \multirow{2}{*}{ Upper lip } & \multicolumn{2}{c}{ Lower lip } \\
& Flow & & & & Central(\%) \\
$\mathbf{1}$ & Type I & 3 & $3.66 \%$ & 27 & $32.93 \%$ \\
$\mathbf{2}$ & Type I & 26 & $31.71 \%$ & 26 & $31.71 \%$ \\
$\mathbf{3}$ & Type II & 19 & $23: 17 \%$ & 27 & $32.93 \%$ \\
$\mathbf{4}$ & Type III & 3 & $3.66 \%$ & 0 & $0.00 \%$ \\
$\mathbf{5}$ & type IV & 16 & $19.51 \%$ & 0 & $0.00 \%$ \\
$\mathbf{6}$ & type V & 15 & $18.29 \%$ & 2 & $2.44 \%$ \\
\hline & Total & $\mathbf{8 2}$ & $\mathbf{1 0 0 . 0 0 \%}$ & $\mathbf{8 2}$ & $\mathbf{1 0 0 . 0 0 \%}$ \\
\hline
\end{tabular}

Table 2 is seen that the upper lip and the groove central most appear are groove type I as many as 26 subjects $(31.71 \%)$ and the least central groove is the groove type III appears that as many as 3 subjects $(3.66 \%)$. The central groove which appears most of the lower lip is a groove type II as many as 27 subjects (32.93\%) and a central groove that does not appear in the lower lip is a groove type III and IV.

Table 3. Observations of the median flow on the upper lip and lower lip

\begin{tabular}{cccccc}
\hline & \multicolumn{5}{c}{ Number } \\
\cline { 2 - 6 } & Flow & \multicolumn{3}{c}{ Upper lip } & \multicolumn{1}{c}{ Lower lip } \\
\hline 1 & 0 & 13 & $15.85 \%$ & 39 & $47.56 \%$ \\
2 & 1 & 6 & $7.32 \%$ & 12 & $14.63 \%$ \\
3 & 2 & 18 & $21.95 \%$ & 7 & $8.54 \%$ \\
4 & 3 & 19 & $23.17 \%$ & 11 & $13.41 \%$ \\
5 & 4 & 10 & $12.20 \%$ & 6 & $7.32 \%$ \\
6 & 5 & 5 & $6.10 \%$ & 2 & $2.44 \%$ \\
7 & 6 & 1 & $1.22 \%$ & - & - \\
8 & 7 & 2 & $2.44 \%$ & 1 & $1.22 \%$ \\
9 & 8 & 4 & $4.88 \%$ & 1 & $1.22 \%$ \\
10 & 9 & 1 & $1.22 \%$ & - & - \\
11 & 10 & 3 & $3.66 \%$ & - & - \\
12 & 12 & - & - & 1 & $1.22 \%$ \\
13 & 13 & - & - & 2 & $2.44 \%$ \\
\hline & Total & 82 & $100.00 \%$ & 82 & $100.00 \%$ \\
\hline
\end{tabular}

Based on the results observed that the amount of flow of the median smallest is 0 and the amount of flow of the median of the largest is 13 with number 3 is a plot of the median most emerged that as many as 19 subjects $(23.17 \%)$ and the number 6 and 9 is a plot of the median at least appear respectively in 1 subject $(1.22 \%)$ on the upper lip, and the number 0 is the lead of the the median most appear as many as 39 subjects $(47.56 \%)$ and the number 7,8 and 12 is the median groove that at least appear respectively in 1 subject $(1.22 \%)$ on the lower lip.

Table 4. Results of the fissure tracing data on the upper lip and lower lip

\begin{tabular}{cccccc}
\hline No & $\begin{array}{c}\text { Flow } \\
\text { amount }\end{array}$ & & Upper lip & & Lower lip \\
\cline { 2 - 3 } & Fissure & & & & \\
\hline & & & & & Tracing(\%) \\
1 & 1 & 13 & $15.85 \%$ & 19 & $23.17 \%$ \\
2 & 2 & 42 & $51.22 \%$ & 34 & $41.46 \%$ \\
3 & 3 & 20 & $24.39 \%$ & $19 \%$ & 23.17 \\
4 & 4 & 4 & $4.88 \%$ & 8 & $9.76 \%$ \\
5 & 5 & 1 & $1.22 \%$ & 2 & 2.44 \\
& $6 \%$ & 2 & $6 \%$ & - & - \\
\hline & Total & 82 & $100.00 \%$ & 82 & $100.00 \%$ \\
\hline
\end{tabular}

Table 5. Overall lip print type of upper lip and lower lip

\begin{tabular}{|c|c|c|c|c|c|}
\hline \multirow{3}{*}{$\begin{array}{c}\text { No } \\
1\end{array}$} & \multirow{3}{*}{$\begin{array}{c}\text { Number } \\
\text { Combination } \\
\text { Path }\end{array}$} & \multicolumn{4}{|c|}{ Number of respondent } \\
\hline & & \multicolumn{2}{|c|}{ Upper lip } & \multicolumn{2}{|c|}{ Lower lip } \\
\hline & & 14 & $17.07 \%$ & 4 & $4.88 \%$ \\
\hline 2 & 3 & 3 & $3.66 \%$ & 3 & $3.66 \%$ \\
\hline 3 & 4 & 12 & $14.63 \%$ & & $16 \%$ \\
\hline 4 & 6 & 12 & $14.63 \%$ & 6 & $7.32 \%$ \\
\hline 5 & 7 & - & - & 7 & $8.54 \%$ \\
\hline 6 & 9 & - & - & 9 & $10.98 \%$ \\
\hline 7 & 10 & 10 & $12.20 \%$ & - & - \\
\hline 8 & 21 & - & - & 21 & $25.61 \%$ \\
\hline & tal Combined & 31 & $37.80 \%$ & 16 & $19.51 \%$ \\
\hline \multicolumn{6}{|c|}{ Flow Different } \\
\hline & Total & 82 & $100.00 \%$ & 82 & $100.00 \%$ \\
\hline
\end{tabular}

Based on the results observed that the lips of a combination of at least the same path appears on two subjects and most appeared in 10 subjects. The combination of grooves that appear on the second subject is the same combination that appears most ie 14 subjects (17.07\%) and a combination of grooves that appear on the same 
3 subjects a combination of at least appear as much as 3 subjects (3.66\%). The combination of different grooves between subjects as many as 31 combinations (37.08\%). In addition, it points out that the lower lip combination of at least the same path appears on two subjects and most appeared in 21 subjects.

The combination of grooves that appear on the same 21 subjects a combination of the most emerged that as many as 21 subjects (25.61\%) and a combination of grooves that appear on the same 3 subjects a combination of at least appear as much as 3 subjects (3.66\%). The combination of different grooves between subjects as many as 16 combinations (19.61\%).

Formula fingerprints lip formulated from the four elements of fingerprints lip on top to produce a formula with the format: (Type groove central) (Number of grooves between) (Fissure tracing)(Type fingerprints lip overall) Symbol of the formula are: Sx Pm A / bn Fn Axxx Description: $S=$ Symbol groove central, $P M=$ Symbol lead of the median, $\mathrm{F}=$ Symbol fissure tracing, $\mathrm{A}=$ type fingerprints lip entire $\mathrm{a} / \mathrm{b}=$ Right $/$ Left, $\mathrm{X}=$ type fingerprints lip, $n=$ Number of grooves

The entire observation data fingerprints lips have been obtained from each subject was later included in the formula. The results of the use of the lip prints formula shows that there is no subject that has a pattern of lip prints the same formula.

\section{DISCUSSION}

The results showed that the patterns of fingerprints lip type II is pattetns lips that most appear on all quadrants fingerprints lip with an average of appearance of $45,54 \%$. This is consistent with research showing that fingerprints Saraswati lip type more common in men and women subrace Deutromelayu. ${ }^{9}$

lip type IV fingerprint pattern is a pattern that at least lip prints appear on all quadrants lip prints with the emergence average of $1.83 \%$. This is consistent with research showing that fingerprints Singh lip prints lip type IV is the most rare. ${ }^{10}$ Based on the observation of lip prints all subjects that are divided into six quadrants seen their four pairs of subjects who have the same combination of lip prints on the sixth quadrant.
The results of this study are similar to the results of research conducted Vahanwala and Parekh on 50 women and 50 men, aged 19-21 years showed that $52 \%$ of all research subjects had at least the same type of lip prints on two quadrants. ${ }^{11}$

Based on the results of research and literature that states that lip prints as well as fingerprints can be used as personal identification suggestions can be made lip prints formula based on the formulation of a fingerprint. Jaishankar research results show that lip prints with all its uniqueness in each individual can be used as a tool in the process of personal identification such as a fingerprint. ${ }^{12}$

Formulation of lip prints in this study are based on the existed fingerprint. Fingerprint formulation is the process of determining the formula combine numbers and special characters that indicate the subject and details of the lines of a set of fingerprints. ${ }^{4}$ Stages, processes, criteria and Award symbols pursued in line with the formulation of fingerprints to obtain more specific results. The main types of fingerprint changed to the central groove type lip prints on the consideration that every part of the lip has different pattern ${ }^{13}$,so that the determination of the main grooves must follow a statute.

Chronology of the median on fingerprints lips than the ridge counting on fingerprint with balance that core fingerprint is replaced with grooves central to the finger lip because the groove the central part of the fingerprint lip which can be determined by reference contained in the anatomy of the lips and predetermined.

Delta fingerprint is replaced with a first groove that have different types with a central groove on the lip prints with the consideration that the local area from the lip prints damati not too broad that it will provide specific groove pattern. In addition, between the groove there will be a number of different grooves on each person.

Fissure tracing the lip prints replace the ridge tracing in fingerprint on the basis that section groove on the lip prints an unspecified amount and the type is the groove that is beside the central groove. Ridge tracing the search process or follow the path of the line on which followed from the delta left until it reaches a point that is parallel to the right of the delta. ${ }^{4}$

Type of lip prints a whole is determined from 
left to right on the upper lip and lower lip. This topographic division is done by refering the topographic division lip prints made by Hassan and Fahmi. Lip prints data in this study included in the formula that has been formulated to show that there is no lip prints occurs with the same pattern from all study subjects. According to Jaishankar research showed that each individual has different lip prints. ${ }^{1}$

Opportunities emergence lip prints the same on each of the upper and lower lips through quadrant division method is equal to $1: 216$, in which each quadrant has the possibility to have six types of lip prints. Opportunities emergence fingerprint same lips on each of the upper and lower lips through the application of the formula fingerprint that is equal to $1: 217728$, where the groove type central has 6 possible types that will appear, the flow of the median has two possible directions with 14 variations in the number, fissure tracing has two possible directions with six variations of the number and type of groove entirely have as many as 216 .

The specification of the lip print pattern in subrace Deutromelayu between individuals can be identified by fingerprints lip formula modification techniques set forth in formula consisting of a central groove type element, the number of grooves between, fissure tracing and types of lip prints.

\section{CONCLUSION}

Lip print pattern among Deutromalayan subrace was identified by modification of lip print formulation technique that was clarified on the formulation.

\section{REFERENCES}

1. Kavitha B, Einstein A, Sivapathasundharam, TR Saraswathi. Limitations in forensic odontology. J Forensic Dent Sci. 2009;1(1):8-10.
2. Reddy LVK. Lip prints: An Overview in Forensic Dentistry. J.AdvDentRes. 2018;2(1):17-20. DOI: https: / / doi.org/10.1177/2229411220110104

3. Saraswathi TR, Mishra G, Ranganathan P. Study of lip prints. J Forensic Dent Sci. 2009;1(1):2831. DOI: $10.4103 / 0974-2948.50885$

4. Ramdhani R, Rizal MA. Software design fingerprint formula in the form of fingerprint whorl types. National Seminar Application of Information Technology. SNATI 2009; Yogyakarta ISSN: 1907-5022

5. Police Identification Center. 1993. Guidancedactyloscopy. Police Headquarters.

6. Rizqiani, Design software calculation formula loop typefingerprint.Proceedings Sentia State Polytechnic of Malang. 2009

7. Eckert WG. Forensic Odontology. In: Introduction to Forensic Sciences. $2^{\text {nd }}$ edition. Boca Raton: CRC Press. 1997. p.385

8. Notoatmodjo, S. Methodology Health Research. $2^{\text {nd }}$ Ed. Jakarta: Rineka Create. 2001

9. Saraswati DD. Variation Pattern Lip print Men and Women Subras Detromelayu as Data Forensic odontology Faculty of Dentistry, University of Padjadjaran. Essay. Dentistry UNPAD. Bandung. 2009.

10. Singh $\mathrm{H}$, Pankaj C, Ritu S. Lip prints asevidence. J Punjab Acad Forensic Med Toxicol 2011; 11(1):23-24.

11. Vahanwahal SP, Parekh DK. Study of lip prints as an aid to forensic methodology. Ind J Dent Assoc. 2000;71: 269-271.

11. Jaishankar S, Jaishankar N, Shanmugam S. Lip Prints in personal identification. J Ind Academy Dent Spec. 2010;(1)4.

12. Maheswari, TNU \& Gnanasundaram, N Role of Lip prints in Personal Identification and criminalization. Anil Aggrawal's Internet Journal of Forensic Medicine and Toxicology [serial online], 2011; Vol. 12, No. 1 (January - June 2011): [about 21 p]. Available from: https://anilaggrawal.com/ij/vol_012_ no_001/papers/paper005.html. 